Enhancement of dental implants esthetics in the IMPLANT THERAPY OUTCOMES, SURGICAL ASPECTS upper anterior zone by the use of connective tissue
grafts: Case series and literature review.

\author{
Zempila M., Malamoudi G., Tsachouridou I., Zekeridou A., Doufexi A.E.
}

Dept. of Preventive Dentistry, Periodontology and Implant Biology, School of Dentistry, Aristotle University of Thessaloniki, Greece.

\section{Background and Aim}

In implant therapy, the adequate state of periimplant tissue health and esthetics, is the essential criterion of restorative success. The need for keratinized mucosa for the maintenance of periimplant health and soft tissue integration remains a debated issue. When it comes to the upper esthetic zone, the choice is much easier since the demands for higher esthetics are always an issue.

The purpose of this poster is to provide a review of the literature evidence concerning the significance of keratinized mucosa on implant health and esthetics. Clinical implant cases treated with connective tissue grafts, are being presented.

\section{Methods and Materials}

Two clinical implant cases in the esthetic upper zone which were treated with connective tissue grafts, are being presented. An electronic search of five databases and a hand search of peerreviewed journals for relevant articles were performed up to January 2017. The keywords used were the following: gingiva, peri-implantitis, review, dental implants, gingival recession, implant esthetics. Screening titles, abstracts and full texts included only English-language publications.

\title{
\begin{tabular}{l|ll} 
Case 1 & Connective tissue graft at 2 nd stage surgery of implant \#13
\end{tabular}
}
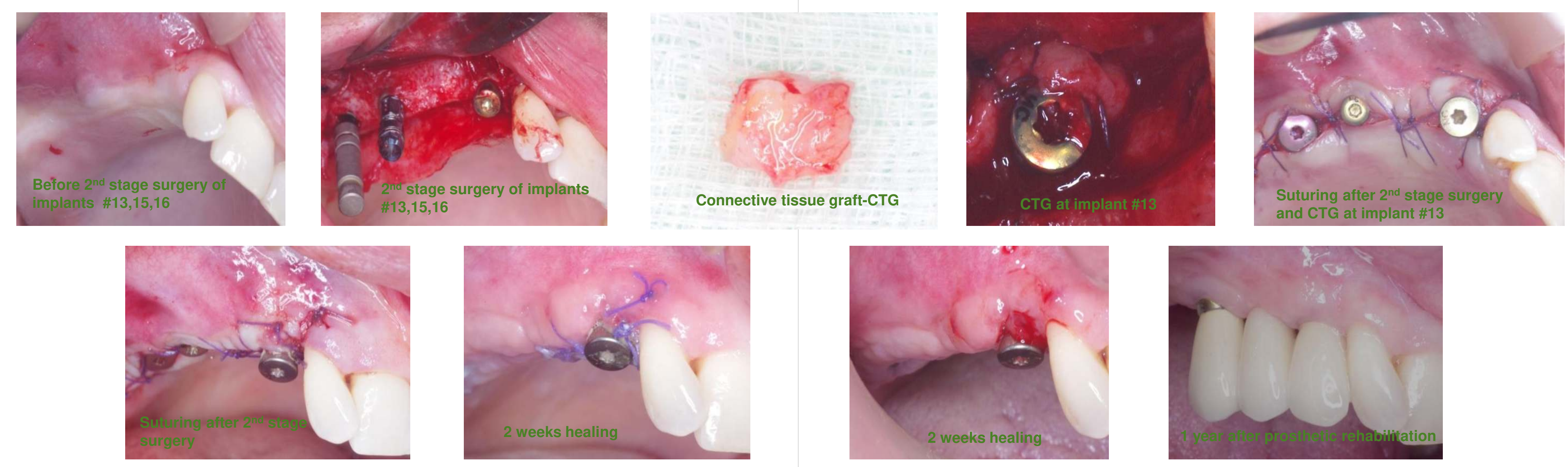

Case 2

GBR at installation and connective tissue graft at 2nd stage surgery of implant \#13

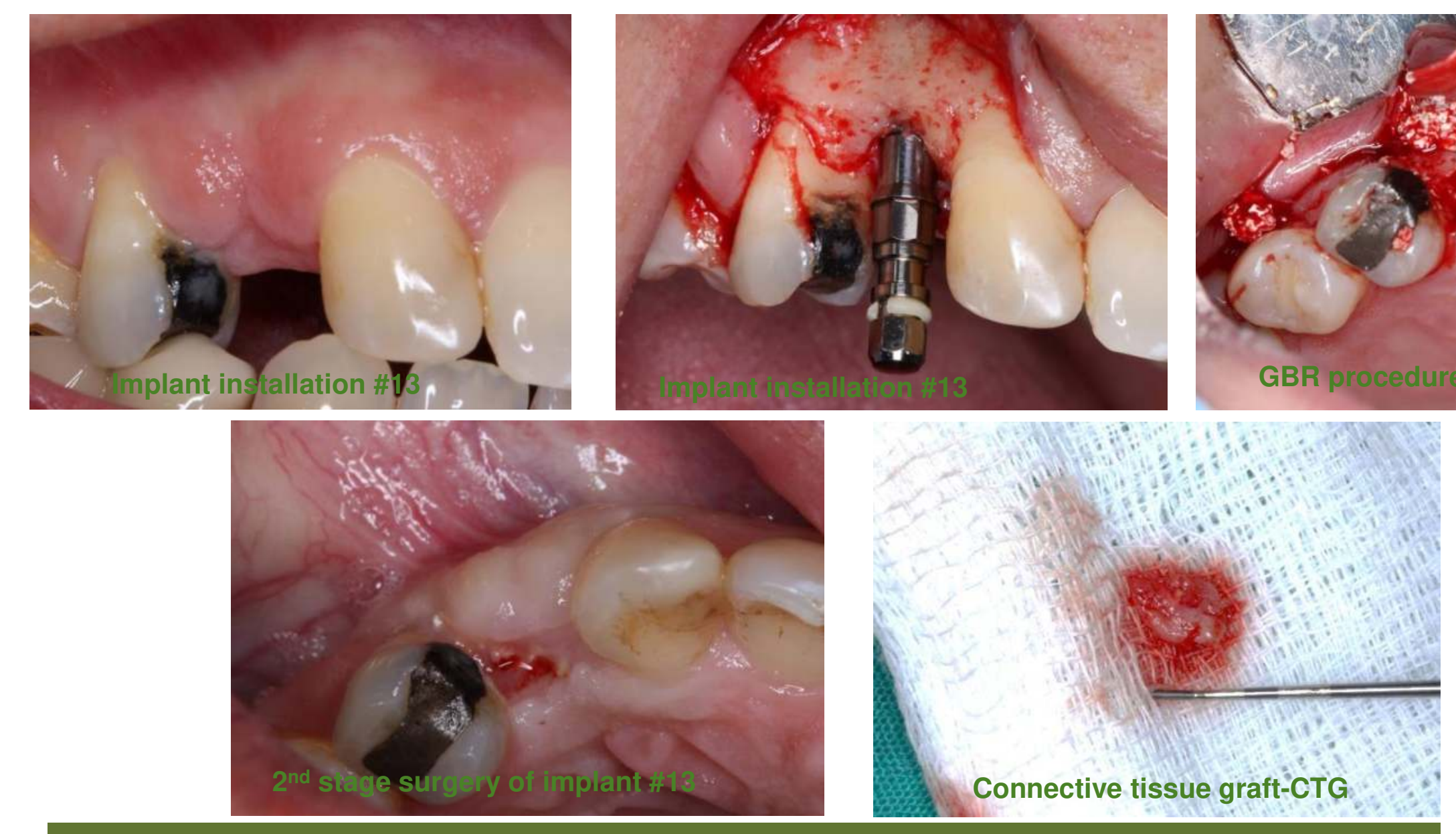

Results

Evidence in support of the need for keratinized tissues around implants to maintain health, tissue stability and esthetics is limited. Reduced keratinized mucosa width around implants appears to be associated with clinical parameters indicative of inflammation and poor oral hygiene. However, based on the selected evidence, the predictive value of keratinized mucosa width is limited. The presence of an adequate zone of keratinized tissue may be necessary when it comes to the esthetic upper zone, because it was shown to be related to better peri-implant tissue health and esthetics.

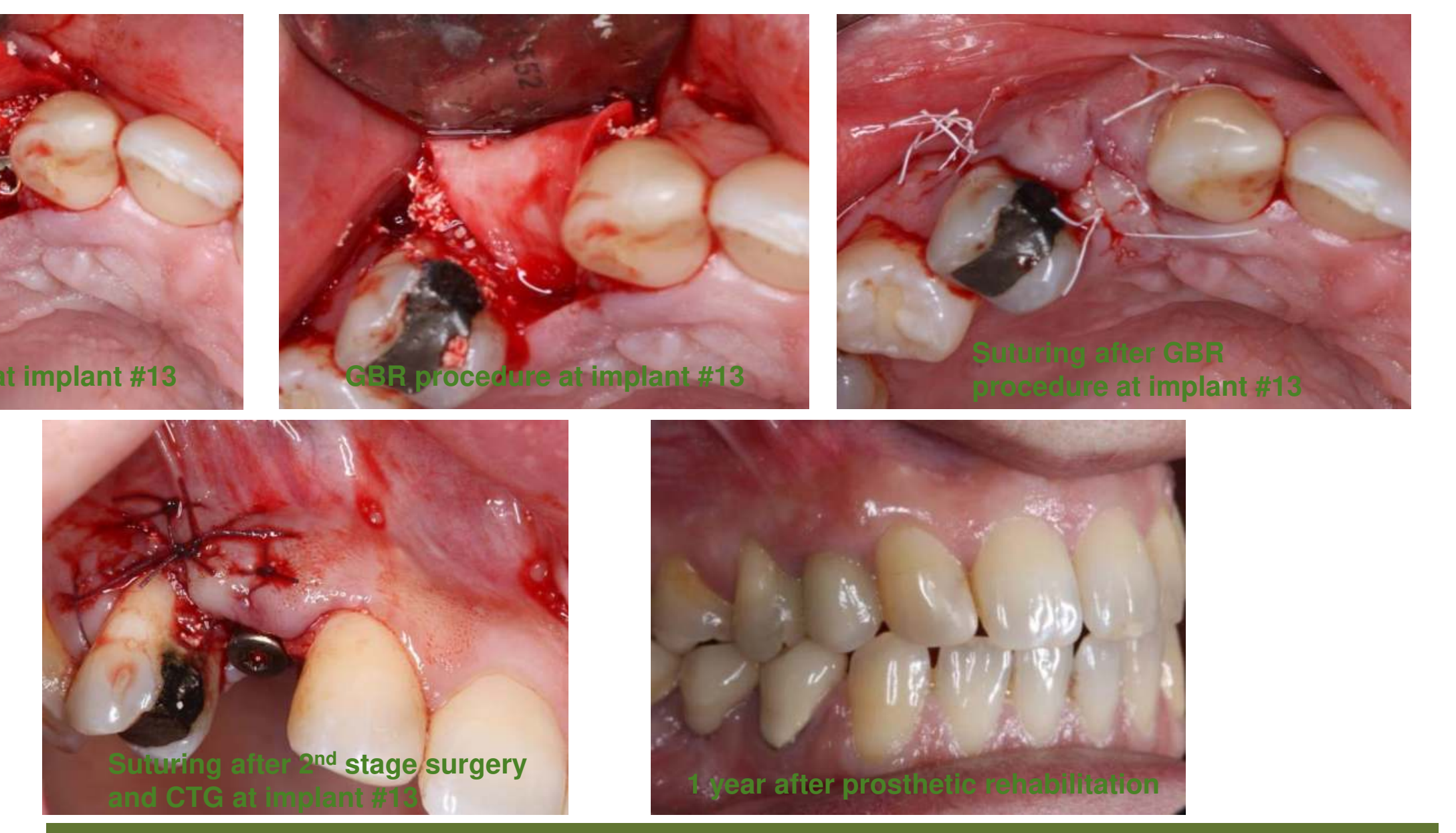

Conclusions

Implants that are not surrounded by keratinized tissues are more prone to plaque accumulation and gingival recession, even in patients exercising sufficient oral hygiene and receiving adequate supporting periodontal therapy. Additional surgical soft tissue manipulations may be necessary especially in cases of high esthetic demands.

\section{References}

1. Brito C., Tenenbaum H.C., et al. Is keratinized mucosa indispensable to maintain peri-implanthealth? A systematic review of the literature. $J$ of Biomed Mat Res B: Appl Biomat 2014; 102B: 3.

2. Lin G., Chan $H_{\text {., }}$ and Wang $H$. The significance of keratinized mucosa on implant health. A systematic review. J Periodontol 2013.

3. Roccuzzo M., Grasso G., and Dalmasso P. Keratinized mucosa around implants in partially edentulous posterior mandible: 10-year results of a prospective comparative study. Clin. Oral Impl. Re. 2016; 27: 491-96. 